\title{
Does Court Type, Size and Employee Satisfaction Affect Court Speed?. Hierarchical Linear Modelling With Evidence from Kenya
}

\author{
Marang'a Moses \\ Kenyatta University, School of Economics \\ E-mail: mosesmaranga@gmail.com
}

\begin{abstract}
In most judicial institutions, well-functioning courts are usually expected to process a large volume of work within demanding timelines. For courts to have played their role of enhancing access to justice, the yardstick of success is often viewed through the lens of the speed attained in rendering justice. In Kenya, despite the desirable timeline for finalizing most of the cases being 'within 360 days' from the date of case filing in courts, by the end of June 2020, 58 per cent of the unresolved cases had surpassed this timeline and subsequently classified as backlog. In the period 2018/19, the percentage of civil cases that were resolved within the set timeline by High Court and Magistrate Court, the two largest court types by volume of work, was 37 and 42 per cent respectively. Over the same period, the percentage of criminal cases that were resolved within the set timeline was 42 and 84 per cent for the two court types respectively. Evidently therefore, the Kenyan courts had not managed to resolve cases within the desirable timeline. To unearth the reasons that could be occasioning the delay, this study investigated the factors that were potentially affecting court speed. Specifically, the study set out to determine the variation in court speed attributable to court type, and further analyze the effect of court size and employee satisfaction on court speed. This was achieved through the use of Hierarchical Linear Modelling, cross sectional data for the period 2018/19 and estimation using Restricted Maximum Likelihood technique. The results revealed the existence of relatively high variation in court speed that is attributable to court type, and that the smaller the court size, the higher the court speed. Further, high level of employee satisfaction was found to increase timely resolution of cases. Consequently, diverse strategies and policy actions for enhancing court speed have been suggested.
\end{abstract}

Keywords: Court Speed, Court Type, Court Size, Employee Satisfaction, Hierarchical Linear Modelling DOI: $10.7176 / \mathrm{JLPG} / 110-02$

Publication date: June $30^{\text {th }} 2021$

\section{Background}

1.1 Introduction

Courts are institutions mandated to render justice through the application and interpretation of laws, and within an environment that requires the observance of principles of rationality and impartiality. To render justice in the most accessible and desirable way, and to all persons, the context requires an environment characterized by maximizing resolution of cases and minimization of time taken to resolve the cases. The maxim that justice delayed is justice denied, associated with the British national William E. Gladstone (1809-1898), accentuate the importance of minimizing the time taken to resolve cases. The minimization of time is often emphasized from the perspective of the person seeking justice. This implies that the time taken by courts to resolve cases is critical to the justice experience, and in many instances, critical in determining whether or not people consider the justice system to be just and fair (Sourdin \& Burstyner, 2014). Slow adjudication speed by courts is therefore undesirable both from the court's leadership and user's viewpoints.

For courts to have played their role in making justice accessible, the yardstick of success is often viewed through the lens of the speed attained in rendering justice. CEPEJ (2018) affirm that court speed plays a crucial role in upholding the rule of law. Further, access to justice presupposes that resolution of cases is not delayed, with absence of delayed justice being an ideal characteristic of court effectiveness (Marang'a, Kimalu \& Ochieng, 2021). In most judicial institutions, well-functioning courts are usually expected to process a large volume of work within demanding timelines. It has therefore become a priority for these institutions to focus on rendering justice in the most timeous manner. This has created the urgency of adopting work methods that reinforce the realization of high case disposal speed at employee, court and Judiciary leadership levels.

In Kenya, despite the desirable timeline for finalizing most of the cases being 'within 360 days' from the date of their filing, by June 2020, 58 per cent of the unresolved cases had surpassed this timeline and subsequently classified as backlog, with some cases remaining unresolved for over 5 years (Judiciary of Kenya, 2020c). In the period 2018/19, the percentage of civil cases that were resolved within the set timeline by High Court and Magistrate Court, the two largest court types by volume of work, averaged at 37 and 42 per cent respectively (Judiciary of Kenya, 2020b). Additionally, the speed realized in resolving criminal cases was 42 and 
84 per cent respectively for the two court types.

Evidently, the Kenyan courts had not managed to reach the desirable speed of resolving cases. It is in the backdrop of this challenge that this study investigated the potential factors that could be working against the realization of desirable court speed, with an overarching aim of advising policy on timeous administration of justice through courts. Specifically the study aimed at determining the variation in court speed attributable to court type, analyzing the effect of court size on court speed and assessing the effect of employee satisfaction on court speed. The objectives were achieved through regression analysis that employed Hierarchical Linear Modelling (HLM) and estimation using Restricted Maximum Likelihood (REML) technique.

The rest of the paper is organized as follows. The background information to court speed, the dependent variable, is foremost provided. This is followed by brief exposition of the independent variables of interest namely; court size, court types and employee satisfaction. Section 2 provides a review of empirical literature related to court speed. Section 3 presents research methodology covering the design, theoretical framework, empirical model specification, estimation, definition and measurement of variables, data type and sources. The results are discussed in Section 4 with conclusions, recommendations and suggestions for further research being presented in Section 5.

\subsection{Court Speed}

\subsubsection{Optimal Court Speed and Measurement}

Timeliness in delivery of justice is one of the values of a court. It is a subjective concept, which means that it may be defined differently by disputants, legal and other professionals, court staff, court administrators or judges (Sourdin \& Burstyner, 2014). The International Framework for Court Excellence (IFCE) views timeliness of a court as a balance between the time required to properly obtain, present, weigh the evidence, law and arguments, and issue a decision (International Consortium for Court Excellence (ICCE), 2020). Any elapsed time from the commencement of litigation to resolution of cases, other than the time which is reasonably required for pleadings, discovery and court events, is undesirable (American Bar Association (ABA), 1992; Sourdin \& Burstyner, 2014). For instance, courts are at times regarded as untimely and inept in coping with the increasing demand for their services (Moura, Rosa, Santinha \& Valente, 2021). Therefore, the desirable court speed is that which minimizes delay and builds user's confidence in the judicial institution.

Although most court users want their cases to be settled expeditiously, adequate consideration of cases requires careful review and consideration by a court of the evidence adduced and applicable laws. As pointed out by Ostrom and Hanson (1999), realization of high court speed requires examination of the adjudication process from the individual characteristics of suits and defendants, and the factors within the manipulative prowess of the court. Further, on-time case processing requires a balance between the time needed for review and the issuance of a decision by court (ICCE, 2020). This puts pressure on courts to develop desirable timelines for finalizing most of their cases. Resolution of cases outside the desirable timelines haunts the administration of justice, postpones rectification of wrong, postpones vindication of the unjustly accused, crowd courts and interferes with prompt disposition of those cases in which parties are prepared for trial (Ostrom \& Hanson, 1999). Falavigna, Ippoliti, Manello and Ramello (2015) and Voigt and El-Bialy (2016) emphasized that the speed of resolving cases and the ability of a judicial system to avoid unreasonable delays are key ingredients for enhancing efficiency in courts.

Concerning the measurement of court speed, trial length, disposition time, efficiency, case delay and ontime case processing have been utilized. Prominently, the calculation of court speed mostly uses the number of resolved cases. This is straightforward since speed is a reflection of time taken to move between two points, in this context the time elapsed from filing to resolution of a dispute. For instance, court speed is measured using the time standards that support performance, efficient processes and accountability (Sourdin \& Burstyner, 2014). On-time case processing shows the percentage of cases disposed within established timeframes, capturing the period regarded as the desirable or reasonable length of proceedings (ICCE, 2020). Fabri (2017) and Ostrom and Hanson (1999) conceptualized court speed as the percentage of cases disposed within established time reference points.

In absence of data on the actual elapsed time required to process a case, the disposition time (DT) is an ideal alternative for measuring court speed. The DT is calculated by dividing the unresolved cases at the end of a given period with the resolved cases, and then multiplying the product by 365 to give the average prospective court speed, in terms of days for finalizing cases (European Commission for the Efficiency of Justice (CEPEJ) 2018, ICCE, 2020). Di Vita (2010), affirm that court speed is best analyzed using the average duration of disputes in days. Prolonged DT is undesirable as it correlates with an increase in litigation costs and threatens evidentiary quality when memories fade, evidence spoils, or witnesses and litigants die (Voigt \& El-Bialy, 2016). In this study, court speed was measured using the average cases resolved within set timelines following Fabri (2017), ICCE (2020), Judiciary of Kenya (2015), Ostrom and Hanson (1999). 


\subsubsection{Insights on Desirable Court Speed in Kenyan Judiciary}

Article 179 of the Kenyan Constitution provide that justice is rendered expeditiously (Republic of Kenya, 2010). This is further reinforced by the report on institutionalization of performance management in Kenyan Judiciary that emphasized the need for reducing case delay, and in essence spelt out the ideal timelines for finalizing cases and applications from their date of filing. The Kenyan Judiciary, through its performance management framework, measures the speed realized by courts in determining cases from their date of filing. At the beginning of each financial year (FY), courts sets performance targets against the set timelines for finalizing cases, and are then evaluated on the achievements made after the end of the FY.

For most Kenyan courts, the desirable court speed for finalizing both criminal and civil cases from the date of filing is 360 days (Judiciary of Kenya, 2015). Further, the determination of certified urgent and injunction applications from the date of certification and filing is 30 and 60 days respectively. Caseload statistics having all the ingredients for calculating the DT, are also published annually through the State of Judiciary and Administration of Justice Report (SOJAR). For instance, the Kenyan courts registered an overall DT of 443 days in the FY 2018/19 (Judiciary of Kenya, 2020b). Specifically, the Supreme Court (SC) had a DT of 381 days, Court of Appeal (COA) 1,699 days, High Court (HC) 863 days, Employment and Labour Relations Court (ELRC) 1,189 days, Environment and Land Court (ELC) 969 days, Magistrate Court (MC) 386 days and Kadhis' Court (KC) 354 days.

\subsection{Court Size and its Determination}

The optimal performance of a judicial institution is expected to be realized within an environment that has some necessary and minimum initial conditions, and which promotes economies of scale. One characteristic of such an environment is the optimal court size which has been suggested to be a necessary condition for the realization of the desired court output. With policy makers being required to make decisions regarding the optimization of court performance, the choice of an ideal court size has remained part of their reflections. Peyrache and Zago (2016) argue that size inefficiency arises from courts operating on too large a scale which would benefit from a break-up into a number of smaller units. In very small courts, indivisibility may reduce efficiency and hence negatively affect judicial performance while in larger courts, it is easier for individual judges to shirk (Voigt \& El-Bialy, 2016). This points to the need for courts to pursue the establishment of work environment that benefits from size economies, and within the existence of sufficient cases to optimally utilize their judges.

The debate on optimal court size across judicial institutions has been viewed through different perspectives, and has existed for long without explicit clarity. Perhaps this could be attributed to diverse conditions that courts operate in around the world, such that what is ideal for a particular jurisdiction may not hold for the other. For instance, Noam (1981) asserted that despite the long-standing dissatisfaction with the inability of the courts to handle cases with dispatch, the discussion on proper size of a court has not been conclusive. This debate has continued, with jurisdictions resulting to reactionary measures on size adjustments whenever inefficiencies are experienced. For instance, when congestion seems to become intolerable, the policy makers add a few judgeships with some jurisdictions attempting to deviate from such ad hoc approaches by allocating judgeships using population of inhabitants and weighted cases (Noam, 1981).

According to CEPEJ (2013), the optimum court size can be viewed in terms of the volume of court work, demographic diversity, number of judges in a court and their productivity. Further, there is trade-off between the need for specialization which imposes a certain minimum size of courts, and proximity to court users as an access to justice phenomena. Voigt and El-Bialy (2016) asserts that there is no theoretical maximum court size and consequently used the number of judges per inhabitant to determine court size.

In Kenyan Judiciary, a scrutiny of existing policy documents does not explicitly reveal the optimal court size. However, performance reports show courts being classified into different sizes but without explicit indication on optimal court size and whether size dynamics could be influencing performance. When ranking courts on performance, the Kenyan Judiciary classifies courts into size clusters that are assumed to have comparable initial conditions. In the performance evaluation report of the period 2015/16, courts were grouped into different sizes using the number of filed cases (Judiciary of Kenya, 2017) while in the report for the period 2018/19, they were categorized using the number of pending cases (Judiciary of Kenya, 2020b). The two reports did not elaborate on the theory or rationale behind the use of different criteria for court size. Further, courts were not classified into sizes based on the effective workload, an amalgamation of pending cases at the beginning of a period and the filed cases during the same period. In this study, the measurement of court size has combined the pre-existing pendency of cases or the unhandled demand for litigation, the filed cases or incoming demand for litigation, and the existing labourforce, a key input for supplying justice.

\subsection{Court System in Kenya}

The establishment of courts in Kenya is provided in Article 162 and 169 of the Constitution, with courts being broadly classified as either superior or subordinate courts (Republic of Kenya, 2010). The superior courts 
comprise; the SC, COA, HC, ELRC and ELC. The subordinate courts are composed of the MC, KC, court martial and tribunals. Nested within a given court type, are the court stations that are spread across the country. By June 2020, there were 4 COA stations, one SC station, 39 HC stations, 6 ELRC stations, 26 ELC stations, 125 MC stations, 47 KC stations and 20 Tribunals within Kenyan Judiciary (Judiciary of Kenya, 2020c). The Kenyan Constitution, diverse Acts of Parliament and guidelines expound the jurisdiction of the different court types especially on the nature of matters handled. In this study, the matters handled in the superior courts by judges, were hypothesized to be more complex in comparison to those handled in the subordinate courts by judicial officers.

\subsection{Employee Satisfaction in Courts}

Courts are labour intensive institutions and hence labour characteristics may come into play during the provision of court services. In a judicial institution, well-engaged and satisfied employees are deemed to exhibit a positive impact on a court output through exemplary or discretionary effort exerted on assigned duties (ICCE, 2020). The provision of court output consists of a high degree of people contact, hence the importance of employee awareness of the required service quality (Murillo, 2014). Further, the doctrine of employee satisfaction and engagement require employees who are passionate about their job, committed to the mission of the judiciary and as a result, are enthusiastic to put discretionary effort into their work (ICCE, 2020). Such employees would get more work done in less time, are innovative, and their courts are likely to render services expeditiously and satisfactorily.

The employee satisfaction level in Kenyan Judiciary is determined through gathering and analysis of information on diverse elements of satisfaction. These elements are employee competence, training and development, performance, communication, workload, compensation, promotion, commitment, organization trust, workmate relationship, work life balance, facilities and work tools, health and safety measures and complaints handling mechanisms (Judiciary of Kenya, 2020a). Out of the optimal employee requirement of 9,323 personnel, the Kenyan Judiciary had a total of 5,263 employees (Judiciary of Kenya, 2020c). In addition to the apparent gap between the required and existing employee establishment, the satisfaction level of all employees stood at 60 per cent in 2019 down from 64 per cent in 2017 (Judiciary of Kenya, 2020a). The key question was as to whether the satisfaction or dissatisfaction level was impacting on court speed?. To answer the question, this study investigated the effect of employee satisfaction on court speed.

\section{Empirical Literature}

This section briefly explores the empirical literature in relation to court speed. The speed of processing cases by courts from the date of filing to the issuance of final decisions has been argued to be an interplay of diverse justice demand and supply forces, and institutional factors. Accordingly, researchers have been investigating these forces and factors with a view to addressing the bottlenecks that work against expeditious delivery of justice. Nonetheless, literature gap still exist given the diverse contexts and environments that world judiciaries operate in. Additionally, there is divergence in measurement and depth of treatment of court speed, including its estimation approaches and potential drivers.

Fabri (2017) assert that new procedures, information and communication technologies, innovative ways to settle disputes, set timeframes, and efficient court management practices impact on disposition time of cases, a measure of speed. Palumbo, Giupponi, Nunziata and Sanguinetti (2013) affirms that higher litigation rate yield lengthy duration of trials especially if the supply of justice does not adjust accordingly. Economides, Haug and McIntyre (2013) explain that the number of judges and court attitudes influence case duration. Further, productivity of judges and burden of pending cases has been negatively linked to the duration of civil proceedings (Di Vita, 2010). According to Ostrom and Hanson (1999), the speed of a court can be influenced by size and complexity of caseload, organizational and management strategies, seriousness of the charge, jurisdictional practices, resources, legal representation and practitioners' norms.

Researchers have established that the nature of a court caseload determines case processing time. Heise (2000) puts forth that case type and its characteristics, including its legal and factual complexity, party type and local legal culture influence case disposition time. The composition may matter if certain types of cases are inherently more complex and thereby require more court time and attention to resolve. In addition, judges and prosecutors may believe that more serious cases deserve more time and attention from the court, and may subsequently establish explicit or implicit priorities to meet that goal (Ostrom \& Hanson, 1999).

The size of court has also been pinpointed as having the potential to influence court speed. Dalton and Singer (2013) established that court size, measured using the number of authorized judgeships for a court, affect overall case length. Smaller courts were found to be more efficient than larger courts at processing civil cases when more than three attorneys appear in a case. Dimitrova, Grajzl, Slavov and Zajc (2016) established that an increase in caseload leads to a rise in the number of disposed cases both in small and large courts. However, literature on the effect of court size on court speed remains scarce. This study, having provided background 
information on court size in Section 1.3, strived to fill the knowledge gap.

Empirical work on potential effect of court types or court layers on court speed is scarce. Voigt (2016) argues that the supply of justice is dependent on among others, the number of court layers. In determining the effect of court size on court speed, this study has taken into account the existing court layers or hierarchies. This was achieved through the use of intraclass correlation (ICC) under HLM. Additionally, a variable capturing the complexity of cases, which was measured at court type level or layer, was included in the regression analysis.

A few papers have explained the potential relationship between employee characteristics and court speed. Voigt (2016), who focused on court output and not speed, pointed that incentives allocated in particular payment schemes and career possibilities, and the number and quality of staff would impact on court speed. Further, the organizational structure of justice systems influence judicial efficiency especially the existing career path and degree of specialization (Voigt \& El Bialy, 2015). This paper has addressed the literature gap by investigating the potential effect of employee satisfaction on court speed.

Different techniques have been used to estimate the potential factors that influence court speed. Dimitrova et al. (2016) used fixed effect (FE) regression and panel data covering the period 2005 to 2013 for Bulgarian district courts. Gomes, Guimaraes and Akutsu (2016) used multiple regression analysis and data for 27 courts covering the period 2003 to 2012 in Brazil. Falavigna et al. (2015) investigated judicial productivity, delay and efficiency in Italian tax courts between 2009 and 2011 using a directional distance function approach. Dalton and Singer (2013) analyzed the length of completion of civil cases in USA using HLM. Di Vita (2010) investigated the contributors to the duration of civil disputes in Italy using FE regression and panel data for the period 2000 2005. This paper has used HLM given the hierarchical arrangement of Kenyan courts and the suitability of the method in generating variance in court speed attributable to court type.

\section{Research Methodology}

\subsection{Theoretical Framework}

The judicial work is of service production and entails transformation of demand for justice into supply (Ippoliti $\&$ Tria, 2020). Hence, for courts to serve justice, clients have to seek justice. The expeditious delivery or speedy supply of justice is considered to be desirable, and forms part of citizens' expectations when they demand court services. Slow court speed is undesirable since it yields congestion of cases, a negative externality in provision of court services as a public good. This points to the interplay of demand and supply forces on court speed as follows;

Court Speed $=f$ (Demand for Justice, Supply for Justice)

Equation (1) provides the initial conditions or the necessary environment to support the realization of the desirable court speed. The equation depicts a fundamental relationship such that the realization of desirable court speed require litigants to have demanded court services and courts to have consequently supplied justice. The demand for court services is manifested through the workload in a court. According to Beenstock and Haitovsky (2004), judges adapt their efforts proportionally to the current workload. The workload comprises cases which differ in complexity. Including the complexity of cases in Equation (1) yields;

Court Speed $=f$ (Demand for Justice, Supply of Justice, Complexity of Cases)

Courts are labour intensive institutions in rendering justice. This does not imply that courts do not require capital resources. This leads to further theoretical anchoring on a court's production function. The relationship is given by Equation (3).

Court Speed $=f$ (Demand for Justice, Supply of Justice, Complexity of Cases, Labour, Capital)

Courts aspire to move to the state of desirable timeliness in service delivery. The assertion is drawn from the public choice and managerialism schools of thought that emphasize on service quality and customer responsiveness as key ingredients of performance (Moura et al., 2021). Murillo (2014) backs this notion by affirming that well-performing institutions spend time examining their policies and practices to support better use of personnel, and motivate them to achieve desirable results. Equation (3) was therefore further enhanced to reflect the desirable labour characteristic as follows;

Court Speed $=f$ (Demand for Justice, Supply of Justice, Complexity of Cases, Labour, Capital, Desirable Labour Characteristic)

The relationship in Equation (4) envisages the existence of a conducive work environment that would motivate court employees to execute their work assignments in a speedy manner.

\subsection{Empirical Model Specification}

Drawing from Equation (4) on the theoretical underpinning of the potential linkages between court speed and independent variables, an empirical model was specified as follows; 


$$
S=F(X, C C)=f(W L, R C, E S, S Z, C C)
$$

where court speed $(S)$ is a function of $X$, a vector of independent variables observed at court station level, and complexity of cases $(\mathrm{CC})$, observed at court type level. Further, $X$ comprises the variables; workload $(W L)$ representing the demand for justice, resolved cases $(R C)$ signifying the supply of justice, employee satisfaction level $(E S)$ representing the desirable labourforce characteristic and court size (SZ). Labourforce was not included as a distinct independent variable despite the theoretical postulations in Section 3.1. The variable was embedded in the calculation of court size, and there was therefore the need to minimize potential multicollinearity amongst the regressors. Capital was assumed to be fixed in short-run.

Since the Kenyan court stations are nested within a court type, Equation (5) was re-specified to appropriately capture this hierarchical setup of courts as follows;

Where;

$$
S_{i j}=\beta_{0 j}+\beta_{1 j} W L_{i j}+\beta_{2 j} R C_{i j}+\beta_{3 j} E S_{i j}+\beta_{4 j} S Z_{i j}+\varepsilon_{i j}
$$

$S_{i j} \quad$ is the observed court speed for court station $i$ in court type $j$

$\beta_{0 j} \quad$ is the intercept for the $j^{\text {th }}$ court type

$\beta_{x j}$ is the regression slope associated with $X$ for the $j^{\text {th }}$ court type, $x=1,2,3,4$

$W L_{i j}$ is the workload for the $i^{\text {th }}$ court station nested within the $j^{\text {th }}$ court type. The rest of the variables constituting $X$ can be restated in a similar manner

$\varepsilon_{i j} \quad$ is the random error term for court station $i$ nested in the $j^{\text {th }}$ court type. It depicts the difference between the observed and predicted court speed, and is assumed to be normally distributed with a mean of 0 and a variance of $\sigma^{2}$.

The average intercept $\beta_{0 j}$ and slope $\beta_{x j}$ vary across court types. Consequently, the level 2 models were specified as follows;

$$
\begin{aligned}
& \beta_{0 j}=\gamma_{00}+\gamma_{01} C C_{j}+\mu_{0 j} \\
& \beta_{x j}=\gamma_{10}+\gamma_{11} C C_{j}+\mu_{1 j}
\end{aligned}
$$

Where the constituents for Equation (7) are;

$\gamma_{00}$ is the overall mean intercept across all court types adjusted for $X$

$\gamma_{01}$ is the effect (regression coefficient) of level 2 predictor for court type $j$ on level 2 intercept

$C C_{j}$ is the level 2 predictor, in this study the complexity of cases for the $j^{\text {th }}$ court type

$\mu_{0 j} \quad$ is the error term or the difference between the observed and predicted intercept for court type $j$ (or the random effect of the $j^{\text {th }}$ court type adjusted for $X$ on the intercept)

And those for Equation (8) are;

$\gamma_{10}$ is the overall mean slope across all the court types adjusted for $X$

$\gamma_{11}$ is the effect (regression coefficient) of level 2 predictor for the $j^{\text {th }}$ court type relative to level 2 slope

$C C_{j}$ is the level 2 predictor, in this study the complexity of cases for the $j^{\text {th }}$ court type

$\mu_{1 \mathrm{j}} \quad$ is the error or the difference between the observed and predicted slope for court type $j$ (or the random effect of the $j^{\text {th }}$ court type adjusted for $X$ on the slope)

Merging Equations (6), (7) and (8), and simplifying using Equation (5) yields;

$$
S_{i j}=\gamma_{00}+\gamma_{01} C C_{j}+\gamma_{10} X_{i j}+\gamma_{11} C C_{j} X_{i j}+\mu_{1 j} X_{i j}+\mu_{0 j}+\varepsilon_{i j}
$$

Equation (9) is unique due to $\mu_{0 \mathrm{j}}$ and $\mu_{1 \mathrm{j}}$ that allow estimation of the error in a way that cannot be realized using ordinary linear regression.

\subsection{Estimation Technique and Data Analysis}

The study used non-experimental research design since there were no experimental controls of variables in Equation (9). Prior to regression analysis, the summary and correlation statistics were generated and explained. Since court stations are nested within court types, the study used HLM to account for the variance in court speed across the court types. Further, court speed was likely to be more correlated for court stations in the same court type due to the shared work environment. In such a hierarchical setup of courts, the use of the Ordinary Least Squares (OLS) regression could have treated each court station as an independent observation without linkage to its court type.

The seven mainstream court types namely; the SC, COA, HC, ELRC, ELC, MC and KC were used for the analysis. Since the number of the court types could not be varied, there was potential challenge of small sample bias in HLM. Hox and McNeish (2020) assert that there is no applicable rule on sample size at different levels in HLM because the minimum sample size requirement fluctuates based on model complexity, the number of random effects, and the ICC. Nonetheless, they suggest the use of Restricted Maximum Likelihood (REML) 
estimation technique as a remedy to small sample bias in comparison to estimation using Full Maximum Likelihood (FML) method. Since REML takes the uncertainty in the fixed parameters into account when estimating the random parameters, it yields better estimates of variance components especially when the groups are few (Raudenbush \& Bryk, 2002).

Consequently, the study used REML estimation technique, applying Kenward-Roger correction of degrees of freedom (DF) to address the challenge of small sample bias that was posed by the existence of a few court types. The degrees of freedom were computed using the observed information matrix. According to Hox and McNeish (2020), McNeish and Stapleton (2016), the REML technique foremost estimates the small sample bias in standard errors, adjusts the standard errors for the bias, and then determines the effective degrees of freedom on the basis of parameter estimates.

In the first step of estimation, the variance in court speed, with speed being determined at the individual court stations, was partitioned into two proportions, one lying within court stations in the same court type and the second between court types. This was important since only the proportion of variance in court speed between court types could be modelled as a function of court type characteristics. In the context of this study, the effects of court stations were deemed to differ from those of the court type for the cluster mean of the same variable and were therefore estimated by including a court type predictor $\left(C C_{j}\right)$ in the model.

To determine the proportion of variance attributed to court types, a fully unconditional model having no court and court type characteristics was estimated. Under Kenward-Roger correction of degrees of freedom, REML in the first stage leaves the fixed effect out (in this context the regression using level 1 predictors only) and gives more accurate estimates of variance (Kenward \& Roger, 2009; Kenward \& Roger, 1997; McNeish, 2017). From the unconditional or null model, the ICC was then computed. The ICC was used to explain the hypothesized differences in court speed across court types, and further informed the suitability of using HLM instead of ordinary regression.

In the second step of analysis, estimation of the random intercepts model that had the covariates for the fixed effect part in the regression was undertaken. Calculation of fixed effect was done through matrix multiplication using generalized least squares. Third, the intercepts and slopes model was estimated. The STATA statistical software was used for data analysis.

For robustness check of the HLM results, ordinary LS procedures were used. Since heteroscedasticity was encountered at the initial stage of LS regression, cluster robust standard errors were used under the ordinary LS and heteroscedastic linear regressions. Further, there was direct inclusion of court type dummy variables in the LS regression without clustering. This approach drew impetus from Hox and McNeish (2020), McNeish and Kelley (2019) and McNeish and Stapleton (2016) who suggested that an appropriate remedy when the main aim is to determine fixed effect, is to include all possible dummy variables for the clusters and then validly use LS procedures.

\subsection{Diagnostic Tests}

Various diagnostic tests were carried out to ensure that the results were reliable in explaining the research objectives. For the REML estimates, the likelihood ratio (LR) test was used to compare the relevance of HLM to linear model while the $F$ test provided information on joint significance of parameters. The normality test for residuals was undertaken through the aid of histograms. Further, both Akaike's Information Criteria (AIC) and Bayesian Information Criteria (BIC) were used to provide information on model fitting. Regarding ordinary LS regression, heteroscedasticity test was undertaken using Breusch-Pagan/Cook-Weisberg test, multicollinearity test using variance inflation factors (VIFs) and model adequacy using Ramsey RESET test.

\subsection{Definition and Measurement of Variables}

All the variables were in continuous percentage form except the ones which were dichotomous in nature. Except for the variable complexity of cases which was measured at court type level, all the other variables were measured at court station level. Their definitions and measurements are given in Table 1. 
Table 1: Definition and measurement of variables

\begin{tabular}{|c|c|}
\hline Variable & Definition \\
\hline Court speed $(S)$ & $\begin{array}{l}\text { Time taken by a court to determine } \\
\text { cases from filing date to conclusion }\end{array}$ \\
\hline $\begin{array}{l}\text { Employee } \\
\text { satisfaction }(E S)\end{array}$ & $\begin{array}{l}\text { Contentment of employees on work } \\
\text { and towards the organization }\end{array}$ \\
\hline $\begin{array}{l}\text { Resolved cases } \\
(R C)\end{array}$ & $\begin{array}{l}\text { Cases finalized or concluded in a } \\
\text { given period of time }\end{array}$ \\
\hline Workload ( $W L)$ & $\begin{array}{l}\text { Disputes or cases before a court } \\
\text { requiring a resolution }\end{array}$ \\
\hline
\end{tabular}

\section{Measurement}

Percentage of cases resolved within the set timeline of 360 days from the date of filing

Percentage level of satisfaction of all employees in a court

Percentage resolved cases in a court to total resolved cases in all courts

requiring a resolution

Court station size (SZ)

Complexity of cases $(C C)$
The size of a court station in terms of existing workload and human resource capacity

Condition or nature of cases such that their adjudication is involving and requires exerting more effort
Percentage of the sum of pending cases in a court at the beginning of a given period and incoming matters over the same period, to total pending cases in all courts

1 for court stations whose workload per judge or judicial officer was less than the mean and 0 if greater than the mean. For robustness analysis, the median workload per judge or judicial officer was used.

1 for cases handled by superior courts and 0 for cases handled by subordinate courts

\subsection{Study Hypotheses}

First, court speed was hypothesized to vary across court types. Second, court size was considered to potentially influence court speed such that the smaller the court, the higher the expected court speed. Bigger courts were deemed to be characterized by size inefficiencies that would slow down their pace of working. Third, highly satisfied employees were hypothesized to positively influence court speed. Such employees were deemed to exude positive energies that could be harnessed by a court to render justice expeditiously.

In regard to the other variables in Equation (9), resolved cases were hypothesized to have potential mixed effects owing to composition of cases and institutional priorities. If the institutional priority is to clear very old or backlog cases, then such resolved cases would have little bearing on court speed the way it was measured in this study. If the priority is to have an appropriate mix between old and new cases, the likelihood for realization of higher court speed would increase with the number of resolved cases. Higher workload was hypothesized to potentially reduce court speed.

Due to unavailability of information on complexity of cases, a generalized assumption was made that superior courts relatively handle more complex cases in comparison to subordinate courts, with complexity of cases argued to reduce court speed. If cases in superior courts are composed of complex appeals, then such cases may take a longer time to resolve. The non-appeal cases handled by superior courts where the original jurisdiction is enjoyed, are more likely to be complex in nature yielding longer completion time. If the bulk of the workload constitute minor offences, the likelihood of timeous conclusion would be high. Conversely, if the majority of cases are composed of serious offences, then the speed of settling them would be low.

\subsection{Data Type and Source}

The study used secondary cross-sectional data for the period 2018/2019. It was sourced from published reports of the Kenyan Judiciary that were obtained from its official website. These reports were; State of Judiciary and Administration of Justice Reports, Performance Management and Measurement Understanding Evaluation Reports and Employee Satisfaction Survey Reports.

\section{Results and Discussions}

\subsection{Descriptive Statistics, Correlation and Multicollinearity Analysis}

The study data comprised 195 court stations nested within 7 court types. The average court stations per court type was 28 with a minimum of 1 and a maximum of 120 . A total of 126 court stations were subordinate in nature while 79 were superior courts. In regard to the dependent variable court speed, 53 per cent of cases had been resolved within the set timeline of 360 days from the date of filing across all courts. The deviation from the mean of 21 per cent depicted relatively huge variation of case disposal speed, a pointer to the existence of differences amongst court stations. The average speed of superior courts stood at 32 per cent while that of subordinate courts was 64 per cent. The highest speed was registered in $\mathrm{KC}$ at 73 per cent followed by $\mathrm{MC}$ at 63 per cent. The SC registered a speed of 41 per cent, $\mathrm{HC}$ a speed of 40 per cent, COA a speed of 32 per cent, ELRC a speed of 25 per cent while ELC had the least speed of 13 per cent.

The size of the courts was determined using the mean workload per employee. This stood at 1,559 cases per 
judge or judicial officer. A total of 112 courts were below the mean and therefore classified as small courts while 83 courts were above the mean and consequently classified as large courts. Using the median workload of 1,421 cases per judge or judicial officer, 98 courts were classified as small and a similar number as large. The difference between the mean and median workload per judge or judicial officer signified an imbalance between courts regarding the demand for justice and the human capital allocated to supply justice.

The average employee satisfaction level stood at 59.73 per cent. This implied a dissatisfaction of 40.27 per cent across courts. The dissatisfaction level was relatively huge and could not be ignored as a factor having the likelihood of affecting the realization of desirable court speed. The minimum employee satisfaction level was 41 per cent while the maximum was 80 per cent. The deviation from the mean satisfaction level was relatively mild at 5.92 per cent.

The mean resolved cases to total cases was 0.52 per cent. This showed that on average, each court contributed less than 1 per cent to total resolved cases. The highest percentage for a single court stood at approximately 5 per cent. In regard to the workload of a court to total workload, the mean stood at 0.52 per cent. The deviation from the mean of 0.72 per cent pointed to the existence of relatively huge differences on workload across courts. Additional summary statistics are given in Appendix 1.

The correlation among the variables was determined prior to regression analysis with results being within acceptable expectations. The highest correlation between the independent variables and court speed was that of complexity of cases at negative 72 per cent followed by that of the employee satisfaction at 34 per cent and resolution of cases at 15 per cent. Additional details on correlation amongst the regressors are provided in Appendix 2. All the regressors had a mean VIF of 2.52 (See Appendix 8). This was within the acceptable bounds of less than 10, an indication that multicollinearity amongst the independent variables was not a problem.

\subsection{Diagnostic Tests Results}

Before the regression results were used to explain the research objectives, diagnostic tests were carried out and interpreted. From the unconstrained model, the chi statistic of 162.62 for the LR test was used to compare the HLM versus the Linear Model. Since the statistic had a $p$-value of 0.0000 , the null hypothesis that random intercepts were equal to zero was rejected, affirming that HLM estimates significantly differed from OLS estimates of standard errors. This justified the use of HLM. The results were comparable when slopes and intercepts were included in the final model with a chi statistic of 51.13 and a $p$-value of 0.0000 reinforcing the use of HLM.

In the final REML results, the $F$ test for the joint significance of parameters was 17.06 with a $p$-value of 0.0000. This showed that the independent variables were jointly reliable in predicting court speed. The histograms of predicted level-1 and standardized residuals illustrated in Appendix 9 portrayed normal distribution of residuals. On model fitting, AIC and BIC were used. From Appendix 6, the random slopes and intercepts model had the lowest AIC and BIC of 1518.94 and 1545.13 respectively in comparison to the random intercepts only (See Appendix 4) and the null models. The tests results supported the use of the REML estimates in explaining the research objectives.

In relation to the LS estimates that were used for robustness check of the HLM results, the BreuschPagan/Cook-Weisberg test for heteroskedasticity had a chi statistic of 20.74 and a $p$-value of 0.000 . This indicated presence of heteroscedasticity. The challenge was addressed through the use of robust standard errors. The Ramsey RESET tests for the two LS regressions; the regression which used cluster robust standard errors and the other one which used court type dummy variables instead of clustering, had an $F$ statistic of 0.46 and 1.07 with $p$-value of 0.7082 and 0.3653 respectively. This showed that the models were well specified and did not suffer from omitted variables.

The adjusted $R$-squared of 0.59 and 0.71 for the LS regression results (2) and (4) in Table 3 meant that 59 and 71 per cent of variation in court speed was explained by the study variables. The adjusted $R$-squared of 0.71 for the LS estimates that were generated using dummy variables for court types rather than court type as a cluster, was higher than the 0.59 per cent that was generated from cluster based LS regression. This pointed to possible existence of other unexplained dynamics within court types that could be affecting court station speed, an assertion that was firmed up by the non-significant constant term in the LS regression that had used court type dummy variables. Additional information on diagnostic tests for the LS estimates is provided in Appendix 7.

\subsection{Study Results and Discussions}

\subsubsection{Variation in Court Speed Attributed to Court Type}

Court speed was hypothesized to vary across court types. To ascertain this, and as a first step in HLM, regression of the unconstrained model was undertaken using REML estimation technique. The technique utilized court type as the group variable and applied Kenward-Roger correction of degrees of freedom to account for the small number of court types. The results are given in Table 2. 
Table 2: One-way ANOVA (Null Model) estimates

\begin{tabular}{|c|c|c|c|}
\hline Court speed & Coefficient & Standard Error & $\mathbf{t}$ \\
\hline Constant & 41.235 & 8.27092 & 4.99 \\
\hline Random-effects Parameters & & Estimate & Standard Error \\
\hline $\operatorname{var}($ constant $)$ & & 437.4056 & 264.5291 \\
\hline var(Residual) & & 176.3579 & 18.16763 \\
\hline LR test versus linear model: c & 1) $=162.62$, & chibar2 $=0.0000$ & \\
\hline
\end{tabular}

Subsequently, the ICC was calculated to determine the percentage of variance in court speed attributable to court type. From the results in Appendix 3, the ICC of 0.7127 meant that 71 per cent of variance in court speed was attributable to court type. The finding resonated with the assertion by Voigt (2016) that the supply of court output depends on among others, the court layers. Though the study by Dalton and Singer (2013) analyzed the length of completion of cases in USA using HLM with court stations being the group variable, its outcome for LR test and ICC resonated with this study results regarding the relevance of modelling the nested court phenomena using HLM.

\subsubsection{Effect of Court Size on Court Speed}

For the second and third objectives of the study, REML estimation using the full model with both the intercepts and slopes as outcomes was undertaken. The REML estimation utilized Kenward-Roger degrees of freedom averaging at 125.94 , with minimum degrees being 2.89 and the maximum being 185.23 . The results are given in Table 3.

Table 3: Full model results and robustness analysis

\begin{tabular}{|c|c|c|c|c|}
\hline \multirow[t]{3}{*}{ Study Variables } & \multirow{3}{*}{$\begin{array}{r}\text { (1) } \\
\text { REML } \\
\text { estimates } \\
\text { under HLM }\end{array}$} & \multicolumn{3}{|c|}{ Robustness analysis } \\
\hline & & $(2)$ & (3) & (4) \\
\hline & & $\begin{array}{r}\text { Cluster robust } \\
\text { LS estimates }\end{array}$ & $\begin{array}{r}\text { Cluster robust } \\
\text { heteroscedastic LS } \\
\text { estimates }\end{array}$ & $\begin{array}{r}\text { Robust LS estimates } \\
\text { using court type } \\
\text { dummy variables } \\
\text { instead of cluster }\end{array}$ \\
\hline \multirow[t]{2}{*}{ Employee Satisfaction } & $0.416^{* * *}$ & $0.523 * *$ & $0.576^{* * *}$ & $0.400 * * *$ \\
\hline & $(0.158)$ & $(0.149)$ & $(0.116)$ & $(0.144)$ \\
\hline \multirow[t]{2}{*}{ Court Size } & $10.28 * * *$ & $8.252 * * *$ & $9.258 * * *$ & $10.23 * * *$ \\
\hline & (2.029) & $(1.546)$ & (1.172) & $(1.856)$ \\
\hline \multirow[t]{2}{*}{ Resolution of Cases } & $5.763 * *$ & $5.194 * * *$ & $8.023 * * *$ & $5.856 * * *$ \\
\hline & $(2.555)$ & (1.017) & $(0.691)$ & $(2.628)$ \\
\hline \multirow[t]{2}{*}{ Workload } & $-5.900 * * *$ & $-5.450 * * *$ & $-7.436 * * *$ & $-5.952 * * *$ \\
\hline & (2.113) & (1.312) & $(0.83)$ & (2.782) \\
\hline \multirow[t]{2}{*}{ Complexity of Cases } & $-36.26 * *$ & $-31.26 * * *$ & $-30.19 * * *$ & \\
\hline & $(7.390)$ & (7.109) & $(6.712)$ & \\
\hline \multirow[t]{2}{*}{ Court of Appeal } & & & & -7.833 \\
\hline & & & & (13.18) \\
\hline \multirow[t]{2}{*}{ High Court } & & & & $4.633^{*}$ \\
\hline & & & & $(2.423)$ \\
\hline \multirow[t]{2}{*}{ ELRC } & & & & $-11.41 * *$ \\
\hline & & & & (4.908) \\
\hline \multirow[t]{2}{*}{ ELC } & & & & $-24.21 * * *$ \\
\hline & & & & (1.911) \\
\hline \multirow[t]{2}{*}{ Magistrate Court } & & & & $27.70 * * *$ \\
\hline & & & & $(1.396)$ \\
\hline \multirow[t]{2}{*}{ Kadhis' Court } & & & & $29.87 * * *$ \\
\hline & & & & $(5.561)$ \\
\hline Constant Term & $33.20 * *(12.02)$ & $27.83 * *(8.368)$ & $23.03 * * *(6.722)$ & $6.387(9.115)$ \\
\hline Adjusted R2 & & 0.5948 & & 0.7086 \\
\hline
\end{tabular}

Key: Standard errors in parentheses, $* p<0.1, * * p<0.05, * * * p<0.01$

The results in Table 3 show that the coefficient of 10.28 for the court size was statistically significant owing to its $p$-value of less than 0.01 per cent. Therefore, a court smaller in size than the average court size would be associated with a higher court speed by 10 units holding other variables constant. The coefficient of court size was also found to be significant and with appropriate sign when other regression techniques were used. From Table 3, the magnitude of the coefficient ranged from 8.252 in cluster robust LS estimates to 10.28 in REML estimates with the value for results 3 and 4 lying between the two values.

The finding on the effect of court size on court speed was in line with study hypothesis that smaller courts are speedier while bigger courts are slower. The finding further resonated with earlier results by Dalton and 
Singer (2013) who had established that court size affected case length in USA. Robustness analysis was also undertaken using the median workload per employee as a measure of court size. Table 4 compares the results generated using both the mean and median workload per employee.

Table 4: Robustness analysis using median court size

\begin{tabular}{lrr}
\hline Variable & $\begin{array}{r}\text { REML estimates using mean } \\
\text { workload per judge or judicial } \\
\text { officer in determining court size }\end{array}$ & $\begin{array}{r}\text { REML estimates using median } \\
\text { workload per judge or judicial officer } \\
\text { in determining court size }\end{array}$ \\
\hline Employee Satisfaction & $0.416^{* * *}$ & $0.408^{* *}$ \\
& $(0.158)$ & $(0.160)$ \\
Court Size & $10.28^{* * *}$ & $9.170^{* * *}$ \\
& $(2.029)$ & $(2.064)$ \\
Resolution of Cases & $5.763 * *$ & $5.482^{* *}$ \\
& $(2.555)$ & $(2.582)$ \\
Workload & $-5.900^{* * *}$ & $-6.167 * * *$ \\
& $(2.113)$ & $(2.137)$ \\
Complexity of Cases & $-36.26 * *$ & $-36.48 * *$ \\
& $(7.390)$ & $(7.466)$ \\
Constant Term & $33.20^{* *}$ & $35.34 * * *$ \\
& $(12.02)$ & $(12.13)$ \\
\hline
\end{tabular}

Key: Standard errors in parentheses, $* * p<0.05, * * * p<0.01$

From the results in Table 4, the coefficient for court size in the estimation that utilized the median court size was 9.170 while another that utilized the median was 10.28 . The difference was relatively minor. Further, the significance level inferred from the $p$-value remained the same. The results for the other variables did not drastically change when the median court size was used. Hence, the use of either the mean or median court size to inform judicial decisions would be appropriate.

\subsubsection{Effect of Employee Satisfaction on Court Speed}

In the third objective, the study aimed at assessing the effect of employee satisfaction on court speed. From Table 3 , the coefficient of 0.416 for employee satisfaction had a $p$-value of less than 0.01 . Therefore, a unit change in employee satisfaction would increase court speed by approximately 0.4 units holding other variables constant. The finding was in line with the hypothesized sign that the higher the satisfaction of court employees, the higher the associated court speed.

Though the satisfaction level of employees had several ingredients accentuated in Section 1.4 in the background, the finding was in line with the assertion by Voigt (2016) who pointed that incentives embedded in payment schemes and career possibilities would impact on court speed. Further, the results supported the finding by El Bialy (2015) who affirmed that organizational structure of justice systems influences efficiency of courts especially the career path and degree of specialization. Using other estimators, the coefficient for employee satisfaction was also found to be statistically significant and having the expected sign. Further, there was no major change of its magnitude in the other results given in Table 3.

\subsubsection{Effect of Other Variables on Court Speed}

The regression model given by Equation (9) comprised other fundamental variables that had been theorized to potentially affect court speed. These variables were the complexity of cases, resolved cases and workload. From Table 3, the coefficient for complexity of cases had a $p$-value of less than 0.05 per cent and the appropriate anticipated negative sign. This implied that, holding other factors constant, the more complex the cases are, and especially in superior courts, the slower the court. The finding resonated with Ostrom and Hanson (1999) affirmation that court speed is influenced by among other factors, the complexity of cases, and Heise (2000) that case characteristics, especially legal and factual complexity, influence disposition time.

The finding was robust to the results that were obtained from LS regression. This is depicted by coefficient -31.26 and -30.19 for the results marked (2) and (3) in Table 3 respectively. From the LS estimates that had utilized court type dummy variables instead of clustering, the effect of complexity of cases on court speed was re-affirmed by the sum of significant coefficients for superior courts of -30.99 , which was comparable to -36.26 that was obtained under REML estimation.

Other results in Table 3 show that the coefficient for resolution of cases of 5.763 was significant at 5 per cent level. Therefore, a unit increase in resolution of cases would increase court speed by approximately 5.8 units holding other factors constant. Since the hypothesized sign for the coefficient was either a plus or a minus, the plus sign depicted that Kenyan courts were appropriately mixing old and new cases during cause-listing. Perhaps exploring the appropriate mix for the old and newly filed cases during cause-listing could be researched in future. Additionally, a unit increase in workload would reduce court speed by approximately 5.9 units, ceteris paribus. This is evidenced by the coefficient for workload of 5.9 which was statistically significant at 1 per cent level. The results in Table 3 on workload and resolution of cases were also robust to other estimators. 


\section{Conclusions and Recommendations \\ 5.1 Conclusions}

The study explored the factors that influence court speed with an aim of advising judicial institutions on strategies and policy actions for enhancing the speed of delivery of justice. This was realized through HLM and estimation using REML technique. In the first objective, the study sought to determine the percentage variance in court speed that could be attributed to court type. From the results, 71 per cent of variance in court speed was attributable to court type. The second objective of the study was to analyze the effect of court size on court speed. Smaller courts were found to be characterized by high speed in comparison to larger courts. Third, an assessment of the effect of employee satisfaction on court speed was done. The results revealed that highly satisfied court employees reinforce their courts to timeously resolve cases. The study further established that court speed reduces with complexity of cases, with superior courts being slower than the subordinate courts. Huge workload was found to adversely affect timeous resolution of cases. As courts resolve more cases, the likelihood of reaching higher resolution speed increases. Lastly, the findings were robust to other estimation techniques namely; cluster robust ordinary LS regression, heteroscedastic linear regression and robust LS regression using court type dummy variables.

\subsection{Recommendations}

Court size was found to influence the speed of settling disputes by courts. Hence, judicial systems could devise strategies for ensuring that court size, as far as it is practical, does not vary extensively from the mean court size, or from any other optimally and officially established court size. Since workload is exogenously determined, the primary focus of adjustment could be on labourforce since it may not be rigid in short run and across space. In the instances that labourforce is constrained and inflexible to allow quick adjustments in short run, establishment of new courts near the congested ones would be ideal in easing up the pressure of high demand for justice. This is further reinforced by the summary statistics which revealed a huge deviation of workload from the mean across court stations. For instance, a large court could be downsized through posting additional judges or judicial officers. The desirable scenario would be to avoid instances of some courts having a huge workload per judge or judicial officer in comparison to the others. Further, it would be important for judicial systems to conceptualize court size using workload per judge or judicial officer. Workload per judge or judicial officer is ideal since it simultaneously encompasses demand for justice, which comprises both pending and incoming matters, and the suppliers of justice, primarily the existing labourforce.

The study established that court speed varied across court types. Consequently, the strategic policies to address case delay essentially ought to be tailor made and be predominantly specific to court types, and further largely address the nature of suits in terms of complexity. Complexity of cases was found to be negatively correlated with court speed with an effect of reducing case disposal speed in superior courts. This points that performance measurement standards focusing on timely disposition of cases ought to vary across court types. For instance, the timeline for finalization of cases within 360 days from the date of filing in most Kenyan court types could be adjusted across court types to account for the complexity of cases, and further within court stations to account for their different sizes. The adjustment of timeline to finalize cases between superior and subordinate courts could hover around 30 units as a guide. The suggested variation is inferred from the results on complexity of cases in Table 3 and the average speed reached by different court types presented in Section 4.1.

Courts should maintain an appropriate balance when prioritizing old cases against fresh incoming matters. This was inferred from the finding that the more the resolved cases, the higher the expected court speed. To maintain the balance, the cause-listed matters should contain both old cases (those that have already surpassed the set timelines and hence cannot meet the minimum desired speed) and fresh cases whose resolution within the set timeline is feasible. Judicial institutions could therefore objectively determine court speed, conceptualized using the set timelines, not from all the cases resolved within a given time period, but using only the resolved cases that are within the feasible time period. However, if court speed is conceptualized using the time taken from filing to resolution of cases without having consideration of set timelines, then the speed achieved by courts would be determined appropriately using the entire set of resolved cases. Additionally, judicial systems should put in measures to drastically reduce their stock of old cases in order to effectively subject the incoming matters to resolution timelines.

A fundamental input for production of judicial decisions is its employees. A rise in employee satisfaction was found to positively affect court speed, a result reinforced by the existence of a relatively huge correlation of 34 per cent between the two variables. Further, the summary statistics showed that 40.27 per cent of court employees were dissatisfied. Since judicial institutions are labour intensive, it is proposed that policy measures to motivate employees and hence raise their satisfaction level ought to be embedded in recruitment, promotion and retention decisions. Perhaps the exclusion of this desirable labour trait could have occasioned the failure by some empirical studies to establish significant impact of increase in court labourforce on court output. Further, prompt handling of employee complaints that occasion their dissatisfaction would support efforts to enhance 
case disposal speed.

\subsection{Suggestions for Future Research}

Future research may explore specific factors that could be influencing court speed within specific court types to unearth other court type based underlying issues. Additionally, investigating the factors that impact on the speed of resolving specific case types would accentuate the micro dynamics surrounding the nature of suits. This would then allow comparison and weighting of different case types based on their disposal speed. Future research could also focus on the drivers of individual judges or judicial officers case resolution speed. This would inform interventions for addressing case delay at individual level.

\section{References}

ABA. (1992). Case flow management and delay reduction: General principle. ABA standards relating to court delay reduction. ABA.

CEPEJ. (2018). European judicial systems efficiency and quality of justice. CEPEJ Studies No. 26. CEPEJ.

Dalton, T., \& Singer, J. M. (2013). Bigger isn't always better: An analysis of court efficiency using hierarchical linear modeling. Boston Legal Studies Research Paper Series, Number 13-14.

Di Vita, G. (2010). Production of laws and delays in court decisions. International Review of Law and Economics, 30(3), 276-281.

Falavigna, G., Ippoliti, R., Manello, A., \& Ramello, G. (2015). Judicial productivity, delay and efficiency: A DDF approach. European Journal of Operational Research, 240(2), 592-601.

Gomes, A. O., Guimaraes, T. A., \& Akutsu, L. (2016). The relationship between judicial staff and court performance: Evidence from Brazilian state courts. International Journal for Court Administration, 8, 1. doi:10.18352/ijca.214.

Heise, M. (2000). Justice Delayed: An empirical analysis of civil case disposition time?, Case Western Reserve Law Review, 50(4), 3.

Hox, J., \& McNeish, D. (2020). Small Samples in Multilevel Modeling. In R. van de Schoot \& M. Milocevic (Eds.), Small Sample Size Solutions, 215-225. Routledge. doi:10.4324/9780429273872-18.

ICCE. (2020). Global Measures of Court Performance. Third Edition. Sydney, Australia: Secretariat for the ICCE.

Ippoliti, R., \& Tria, G. (2020). Efficiency of judicial systems: Model definition and output estimation. Journal of Applied Economics, 23(1), 385-408.

Judiciary of Kenya. (2020a). Employee Satisfaction and Work Environment Survey 2019. Nairobi, Kenya: The Judiciary.

Judiciary of Kenya. (2020b). Performance Management and Measurement Understandings Evaluation Report, 2018/19. Nairobi, Kenya: The Judiciary.

Judiciary of Kenya. (2020c). State of the Judiciary and Administration of Justice Annual Report, 2019-2020. Nairobi, Kenya: The Judiciary.

Judiciary of Kenya. (2015). Institutionalizing Performance Management and Measurement in the Judiciary. Nairobi, Kenya: The Judiciary.

Kenward, M. G., \& Roger, J. H. (2009). An improved approximation to the precision of fixed effects from REML. Computational Statistics \& Data Analysis, 53(7), 2583-2595. doi:10.1016/j.csda.2008.12.013.

Kenward, M. G., \& Roger, J. H. (1997). Small sample inference for fixed effects from REML. Biometrics, 53(3), 983-997. doi:10.2307/2533558.

Marang'a, M. W., Kimalu, P. K., \& Ochieng, M. A. (2021). Effect of COVID-19 pandemic on resolution of cases in courts: The Kenyan Judiciary. Research Paper No. 1 of 2021. The Judiciary.

McNeish, D. (2017). Small sample methods for multilevel modeling: A colloquial elucidation of REML and the Kenward-Roger correction. Multivariate Behavioral Research, 52(5), 661-670.

McNeish, D., \& Kelley, K. (2019). Fixed effects models versus mixed effects models for clustered data: Reviewing the approaches, disentangling the differences, and making recommendations. American Psychological Association 2019, 24(1), 20-35. doi:10.1037/met0000182.

McNeish, D., \& Stapleton, L. M. (2016). Modeling clustered data with very few clusters. Multivariate Behavioral Research, 51(4), 495-518. doi:10.1080/00273171.2016.1167008.

Moura, P., Rosa, M. J., Santinha, G., \& Valente, C. (2021). Quality assessment of the services delivered by a court based on the perceptions of users, magistrates and court officials. Sustainability, 13(2), 1-16.

Murillo, R. (2014). Understanding the service quality perception gaps between judicial servants and judiciary users. International Journal for Court Administration, 6(2), 84-105. doi:10.18352/ijca.146

Noam, E. M. (1981). The Optimal Size of the Criminal Court System. In: Sirkin G. (Eds.) Lexeconics. Social Dimensions of Economics, 2. Springer.

Ostrom, B. J., \& Hanson, R. A. (1999). Efficiency, timeliness, and quality: A new perspective from nine state 
criminal trial courts. NCSC.

Palumbo, G., Giupponi G., Nunziata, L., \& Sanguinetti, J. M. (2013). Judicial performance and its determinants: A cross-country perspective. OECD.

Peyrache, A., \& Zago, A. (2016). Large courts, small justice. The inefficiency and the optimal structure of the Italian justice sector. Omega, 64, 42-56.

Raudenbush, S. W., \& Bryk, A. S. (2002). Hierarchical Linear Models: Applications and data analysis methods. Thousand Oaks, CA: Sage.

Republic of Kenya. (2010). Constitution of Kenya. Laws of Kenya, Nairobi, Kenya: The NCLR.

Sourdin, T. M., \& Burstyner, N. (2014). Justice delayed is justice denied. Victoria University Law and Justice Journal, 4(1), 46-60. doi:10.15209/vulj.v4i1.61.

Voigt, S. (2016). Determinants of judicial efficiency: A Survey. European Journal of Law and Economics, 42(2), 183-208.

Voigt, S., \& El-Bialy, N. (2016). Identifying the determinants of aggregate judicial performance: Taxpayers' money well spent?. European Journal of Law and Economics, 41(2), 243-319. doi:10.2139/SSRN.2241224.

\section{Appendices}

Appendix 1: Summary statistics

\begin{tabular}{|c|c|c|c|c|}
\hline Variable & Mean & Standard deviation & Minimum & Maximum \\
\hline Court Speed & 52.57 & 21.19 & 3 & 92 \\
\hline Employee Satisfaction & 59.73 & 5.92 & 41 & 80 \\
\hline Resolution of Cases & 0.52 & 0.72 & 0.01 & 5.29 \\
\hline Workload & 0.52 & 0.82 & 0.01 & 6.24 \\
\hline
\end{tabular}

Appendix 2: Correlation of variables

\begin{tabular}{lrrrrrr}
\hline Variable & $\begin{array}{r}\text { Court } \\
\text { Speed }\end{array}$ & $\begin{array}{r}\text { Employee } \\
\text { satisfaction }\end{array}$ & $\begin{array}{r}\text { Resolution } \\
\text { of cases }\end{array}$ & $\begin{array}{r}\text { Work } \\
\text { load }\end{array}$ & $\begin{array}{r}\text { Court } \\
\text { Size }\end{array}$ & $\begin{array}{r}\text { Complexity } \\
\text { of Cases }\end{array}$ \\
\hline Court Speed & 1 & & & & & \\
Employee Satisfaction & 0.34 & 1 & & & & \\
Resolution of Cases & 0.15 & -0.11 & 1 & & & \\
Workload & 0.01 & -0.14 & 0.87 & 1 & 1 & 1 \\
Court Size & 0.08 & 0.10 & -0.48 & -0.46 & -20 & \\
Complexity of Cases & -0.72 & -0.23 & -0.38 & -0.25 & 0.20 & \\
\hline
\end{tabular}

Appendix 3: Intraclass correlation (ICC) computed from one-way ANOVA

\begin{tabular}{lrrrr}
\hline Level & ICC & Standard Error & [95\% Conf. & Interval] \\
\hline Court type & 0.7127 & 0.1256 & 0.4270 & 0.8920 \\
\hline
\end{tabular}

\begin{tabular}{lr} 
Appendix 4: One-way ANCOVA with random effects & \\
\hline Variable & REML coefficient estimates \\
\hline Employee Satisfaction & $0.416^{* * *}(0.152)$ \\
Court Size & $10.21 * * *(1.99)$ \\
Resolution of Cases & $5.997 * *(2.54)$ \\
Workload & $-6.005 * * *(2.11)$ \\
Constant Term & $8.28(12.30)$ \\
\hline Key: Standard errors in parentheses, $* * p<0.05, * * * p<0.01$ &
\end{tabular}

\begin{tabular}{|c|c|c|c|}
\hline Test Type & Statistic & $p$-value & Conclusion \\
\hline $\begin{array}{l}\text { F test for model } \\
\text { reliability }\end{array}$ & $F(5,23)=17.06$ & Prob $>F=0.0000$ & $\begin{array}{l}\text { Independent variables in the model were } \\
\text { reliable in predicting court speed }\end{array}$ \\
\hline $\begin{array}{l}\text { LR test vs. linear } \\
\text { model }\end{array}$ & $\operatorname{chi} 2(2)=51.13$ & Prob $>$ chi $2=0.0000$ & $\begin{array}{l}\text { The HLM estimates differed significantly from } \\
\text { OLS estimates of standard errors }\end{array}$ \\
\hline \multicolumn{4}{|c|}{ No. of groups $=7$, Minimum $=1$, Average $=28$, Maximum $=120$} \\
\hline
\end{tabular}


Appendix 6: AIC and BIC results for model fitness

\begin{tabular}{lrr}
\hline & AIC & BIC \\
\hline Null model & 1583.963 & 1593.782 \\
Random intercept model & 1533.998 & 1556.909 \\
Random slopes and intercept model & 1518.944 & 1545.128 \\
\hline
\end{tabular}

\begin{tabular}{|c|c|c|c|}
\hline Test Type & Statistic & $p$-value & Conclusion \\
\hline Breusch-Pagan/Cook-Weisberg test & $\operatorname{chi} 2(1)=20.74$ & 0.0000 & There was heteroskedasticity \\
\hline $\begin{array}{l}\mathrm{F} \text { test (LS regression using cluster robust } \\
\text { standard errors) }\end{array}$ & $F(5,6)=8235.7$ & 0.0000 & $\begin{array}{l}\text { All the model parameters were jointly } \\
\text { different from zero }\end{array}$ \\
\hline $\begin{array}{l}\text { Ramsey RESET test (LS regression } \\
\text { using cluster robust standard errors) }\end{array}$ & $\mathrm{F}(3,186)=0.46$ & 0.7082 & $\begin{array}{l}\text { There were no omitted variables and } \\
\text { hence the model was well specified }\end{array}$ \\
\hline $\begin{array}{l}\text { Ramsey RESET test (LS regression } \\
\text { using court type variables instead of } \\
\text { clusters) }\end{array}$ & $\mathrm{F}(3,181)=1.07$ & 0.3653 & $\begin{array}{l}\text { There were no omitted variables and } \\
\text { hence the model was well specified }\end{array}$ \\
\hline $\begin{array}{l}\text { VIF (LS regression using cluster robust } \\
\text { standard errors) }\end{array}$ & Mean VIF $=2.52$ & & Multicollinearity was not a problem \\
\hline $\begin{array}{l}\text { Adjusted R-squared (LS regression using } \\
\text { cluster robust standard errors) }\end{array}$ & 0.5948 & & $\begin{array}{l}60 \text { per cent of variation in court speed } \\
\text { was explained by the model variables }\end{array}$ \\
\hline $\begin{array}{l}\text { Adjusted R-squared (LS regression using } \\
\text { court type dummy variables instead of } \\
\text { clustering) }\end{array}$ & 0.7086 & & $\begin{array}{l}71 \text { per cent of variation in court speed } \\
\text { was explained by the model variables }\end{array}$ \\
\hline \multicolumn{4}{|c|}{ Appendix 8: Variance Inflation Factors (VIF) from LS regression under cluster robust standard errors } \\
\hline Variable & & & VIF $\quad$ 1/VIF \\
\hline Resolution of Cases & & & 4.68 \\
\hline Workload & & & 0.24 \\
\hline Court Size & & & 0.76 \\
\hline Complexity of Cases & & & 0.76 \\
\hline Employee Satisfaction & & & 0.90 \\
\hline Mean VIF & & & 2.52 \\
\hline
\end{tabular}

\section{Appendix 9: Histograms of predicted level-1 and standardized residuals}
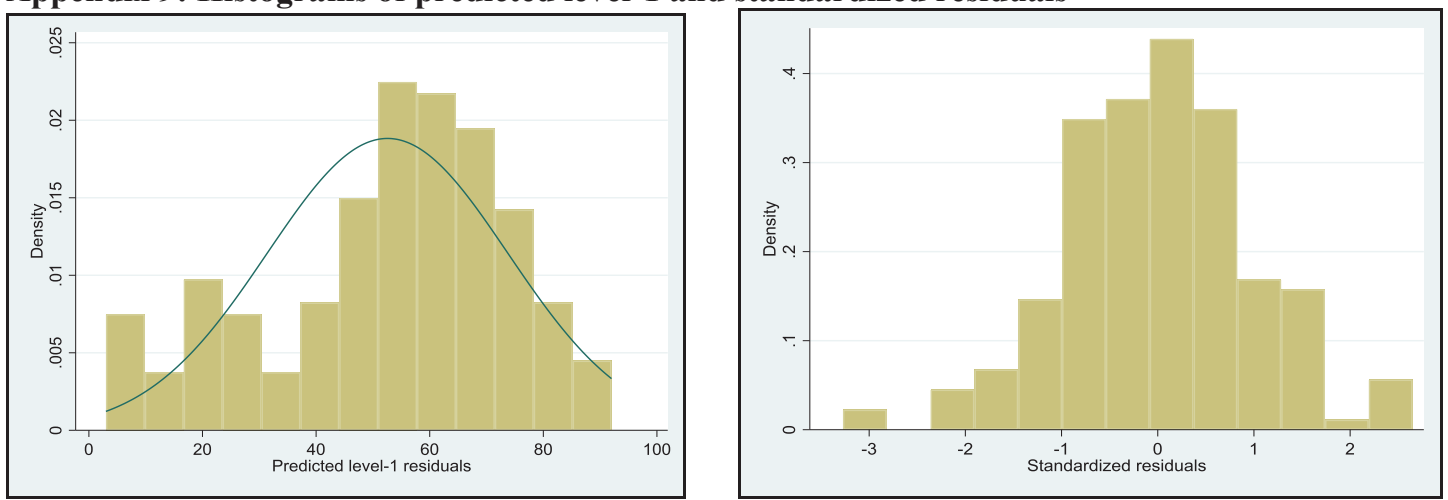

Figure a: Histogram of predicted level-1 residuals Figure b: Histogram of standardized residuals 